\title{
A CONCEPTUAL DESIGN OF THE INTERNATIONAL THERMONUCLEAR EXPERIMENTAL REACTOR FOR THE CENTRAL SOLENOID
}

\author{
J.R. Heim and J.M. Parker \\ Lawrence Livermore National Laborato:y \\ P.O. Box 5511, L-643 \\ Livermore, CA 94550
}

UCRL-JC- -103490

DE91 000655

\section{$\underline{\text { Abstract }}$}

Conceptual design of the International

Thermonuclear Experimental Reactor (ITER) superconducting magnet system is nearing completion by the ITER Design Team, and one of the Central Solenoid (CS) designs is presented. The CS part of this magnet system will be a vertical stack of eight modules, approximately $16 \mathrm{~m}$ high, each having approximate dimensions of: $4.1-\mathrm{m}$ o.d., 2.8- $\mathrm{m}$ i.d., 1.9- $\mathrm{m} \mathrm{h}$. The peak field at the bore is approximately $13.5 \mathrm{~T}$. Cable-in-conduit conductor with $\mathrm{Nb}_{3} \mathrm{Sn}$ composite wire will be used to wind the coils. The overall coil fabrication will use the insulate-wind-react-impregnate method. Coil modules will be fabricated using doublepancake coils with all splice joints located in the low-field region on the outside of the coils. All coils will be structurally graded with high-strength steel reinforcement which is co-wound with the conductor. We describe details of the CS coil design and analysis.

\section{Introduction}

ITER is a large magnetic fusion tokamak machine which is being pursued as an international team effort. A three-year duration, conceptual-design phase is almost complete; and the long-range plan is for the next team effort to be a five-year duration, engineering-design phase. The conceptual design uses superconducting magnets to generate both the torodial fields (TF) and the poloidal fields (PF), with $\mathrm{Nb}_{3} \mathrm{Sn}$ as the superconducting material. The TF coils will operate dc, while the PF coil system is pulsed for normal operation. This pulsed requirement for the PF coil system complicates the superconducting coil design in that the allowable stress limits must be decreased to the material- fatigue allowable stress, and eddy current losses become an important consideration in making design decisions. The CS coils are a tall stack of the smallest diameter coils in the PF coil system, but they are difficult from an engineering stand point because they are compact and high-field coils. The following concept presents a design using eight identical CS coil modules which are stacked vertically and clamped together with a preloading structure. The CS magnet assembly will stand approximately $16 \mathrm{~m}$ in height and will weigh about 820 metric tons. The present plan is to build the C.S magnet as a subassembly and then to install it as a one-piece unit.

\section{Conductor}

The conductor chosen for the CS coils is a forcedflow cable-in-conduit conductor with $\mathrm{i} b 3 \mathrm{Sn}$ superconductor. The cable uses 675 wires fabricated into a $5^{2} \times 3^{3}$ pattern. The wire diameter is $0.89 \mathrm{~mm}$ with a $60 \%$ copper matrix. The conductor has been sized to carry

Manuscript received September 24, 1990.
$39.62 \mathrm{kA}$, which gives a $2 \mathrm{~K}$ temperature margin on the current-sharing temperature for the worst-case conductor in the winding. A detailed description of the method used to calculate forced-flow conductor-stability margins is presented in another paper at this conference. The superconducting cable is enclosed inside a rectangular steel conduit, and the resulting inside area is called the cable space. The cable uses about $60 \%$ of this cable space, with the remaining $40 \%$ serving as a forced-flow channel for the He coolant. A cross section of the CS conductor is shown in Fig. 1. The conduit is made from a high strength, precipitation-hardening steel. The $\mathrm{Nb}_{3} \mathrm{Sn}$ reaction heat treatment and the steel, age-hardening heat treatment are compatible with a furnace temperature of approximately $700{ }^{\circ} \mathrm{C}$. The conductor must be insulated with a high temperature glass or equivalent tape, as the insulation will also be exposed to high heat-treatment temperatures. Conductor insulation is applied as a half-lap spiral wrap to a thickness of $0.8 \mathrm{~mm}$.

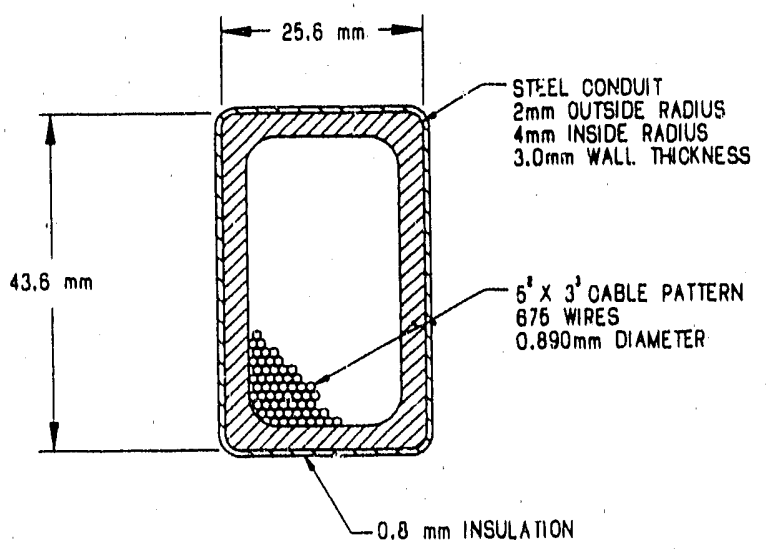

Fig. 1. ITER central-solenoid conductor

\section{Steel Reinforcement}

High strength steel reinforcement is used to limit the coil maximum hoop stress to $400 \mathrm{MPa}$. Like the conductor, the reinforcement is made from a precipitationhardening steel, which age hardens during the Nb3Sn reaction heat treatment, and is also insulated with the same high temperature tape applied as a half-lap spiral wrap to a thickness of $0.8 \mathrm{~mm}$. This reinforcement is co-wound with the coil conductor and is structurally graded to maximize ' \& volt seconds produced by the coils, with no radial tensile stresses in epoxy bonds. A detailed description of the method used to size the reinforcement is presented in another paper at this conference.

\section{Double Pancake Coils}

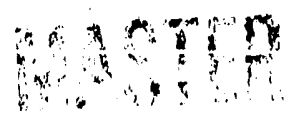

All CS Coils will be wound as double-pancake coils. The He inlet will be located at the crossover, as shown in 
Fig. 2. This decision was made to introduce the lowtemperature inlet $\mathrm{He}$ at the bore of the magnet, which is the high-field region. Each pancake has 13.375 turns, with the double-pancake coil-end terminations spaced $90^{\circ}$ apart, as . shown in Fig. 3. This spacing between coil ends distribures the coil splice joints at four locations on the outside of the coil module. The $90^{\circ}$ displacement from coil-to-coil also gives a more uniform coil-module stiffness in both the radial and axial directions. The winding center of the upper pancake is shifted one-half conductor width with respect to the lower-pancake-winding center to improve the outer radius matching of the two coils. The coil-end terminations are enclosed in a copper sleeve, which is swaged onto the superconducting cable and securely attached to the conductor conduit before heat treatment. This enclosure protects the superconducting cable after heat treatment, when the cable is in a brittle condition. The coilend termination is shown in Fig. 4.

\section{Coil Stacking}

After heat treatment, twenty double pancakes are stacked vertically to make a coil module. The splice joints between double pancakes are made during this stacking operation. The double-pancake coil which is being added to the stack is positioned above the stack with spacers, and the

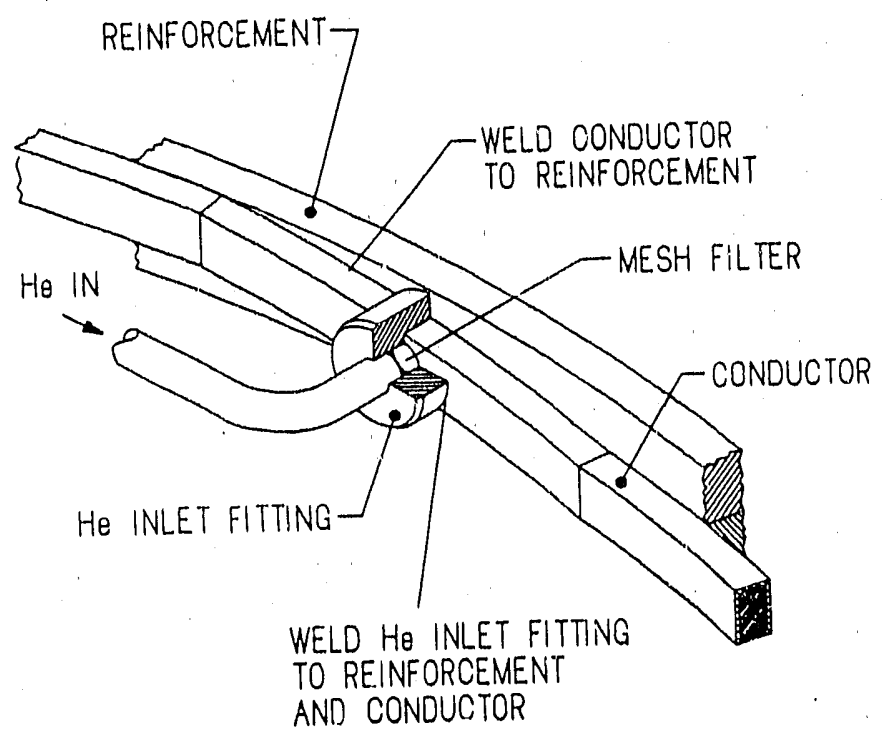

Fig. 2. Double-pancake coil cross over with heilim coolant inlet

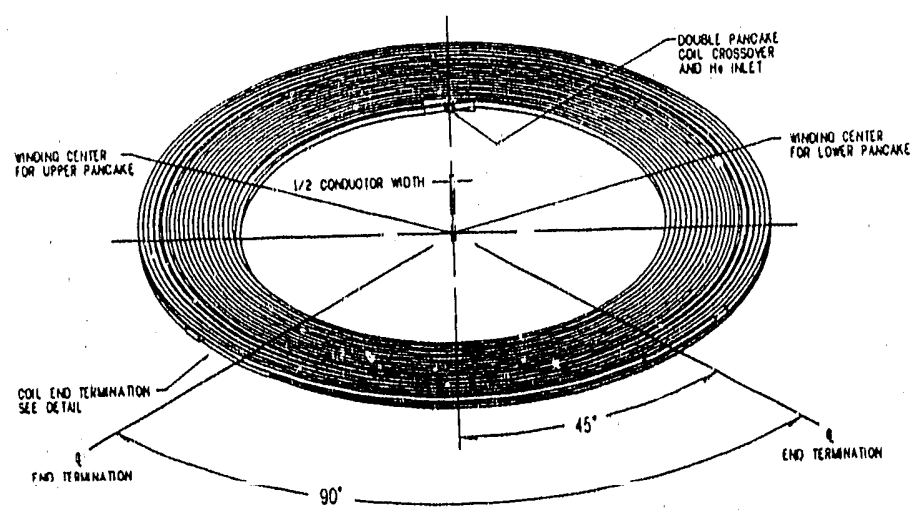

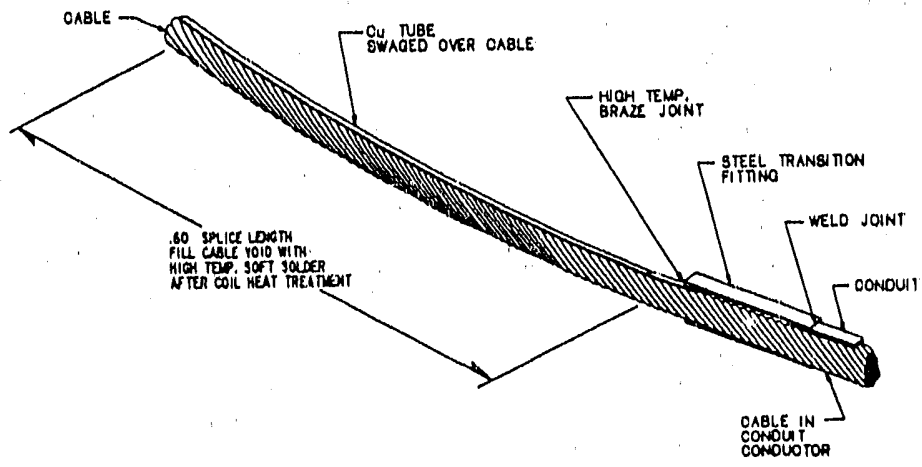

Fig. 4. Coil-end termination design

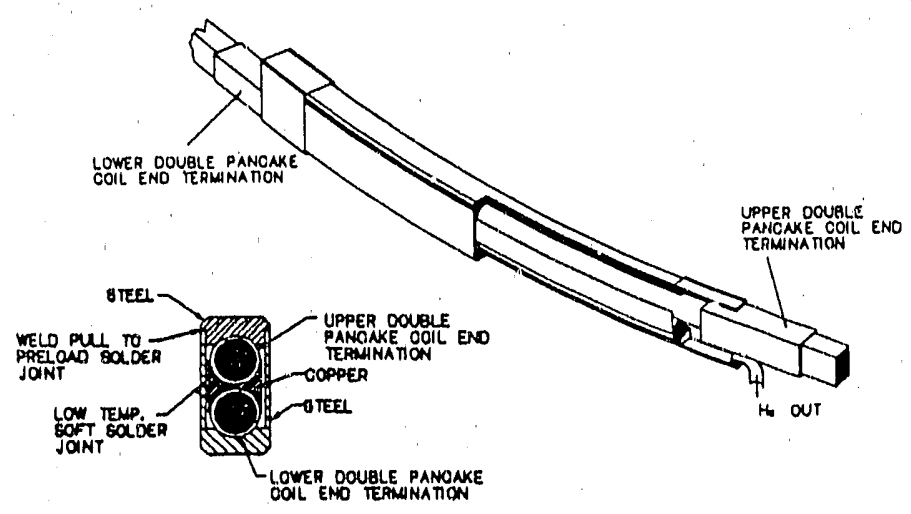

SPLICE CROSS SECTION

Fig. 5. Coil-splice joint

coil-end terminations which are to be joined together are mated and soft-soldered to a common, copper-splice block. After soldering, the joint is encased in a stainless-steel enclosure, and the coil is lowered into place. A coil splice joint is shown in Fig. 5. A He coolant outlet penetrates this stainless-steel enclosure, and the outlet line is routed vertically to the top or bottom of the coil module. Additional insulation ( $0.8 \mathrm{~mm}$ thick) is installed between pancakes, and $5.0 \mathrm{~mm}$ ground-plane insulation is installed on all outside surfaces. The module is then vacuum impregnated with a thermosetting epoxy and cured. A coilmodule cross section is shown in Fig. 6, and a module assembly is shown in Fig. 7.

\section{Module Stacking}

Eight coil modules are stacked vertically to make the CS magnet. Twelve bearing plates which cover approximately $80 \%$ of the module-to-module bearing surface are inserted between modules. The gaps between these plates are used for routing He-coolant outlet lines to insulator canisters located in the bore of the magnet. These lines are at coil potential, and the outside surfaces are insulated. All helium in-line insulators for both inlet and outlet lines are located inside the insulator canisters. The insulator canisters can be assembled and tested as subassemblies prior to installation. The insulator canister design is shown in Fig. $\delta$.

Fig. 3. Double-pancake coil 


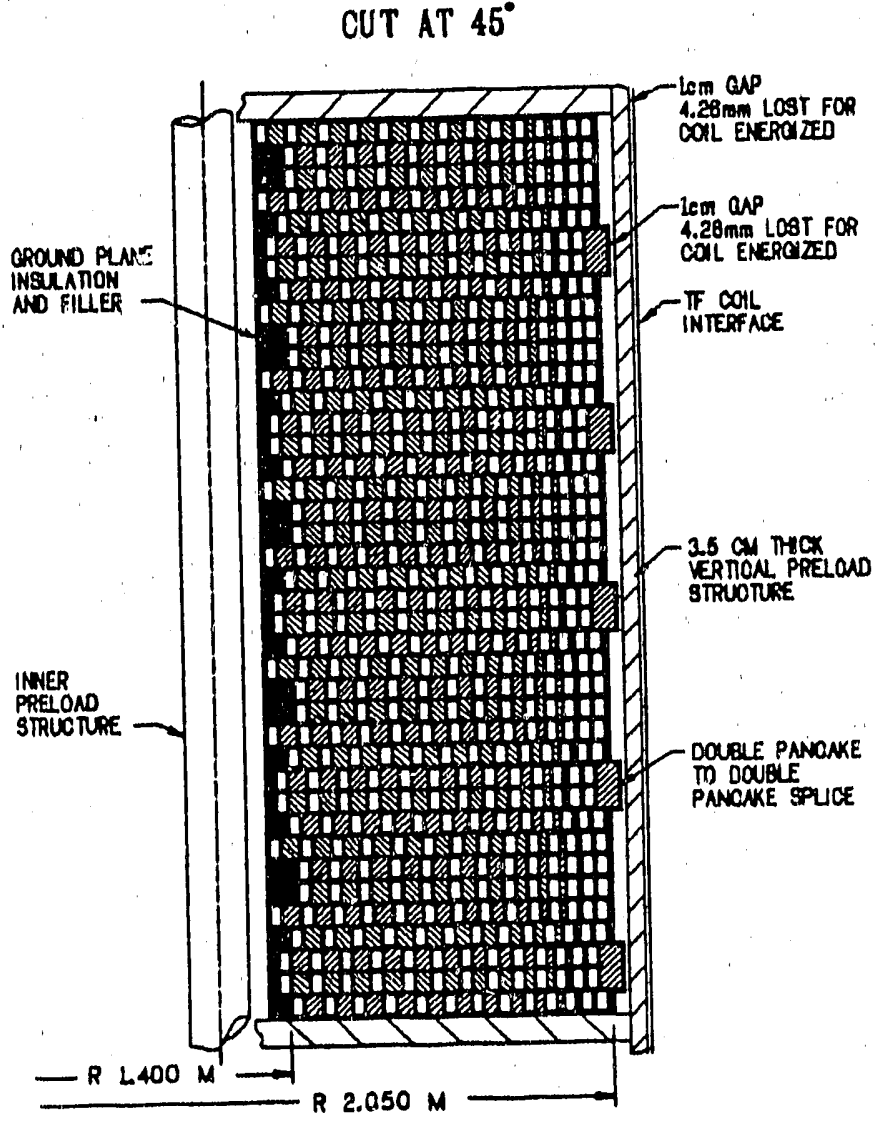

Fig. 6. Coil module cross section

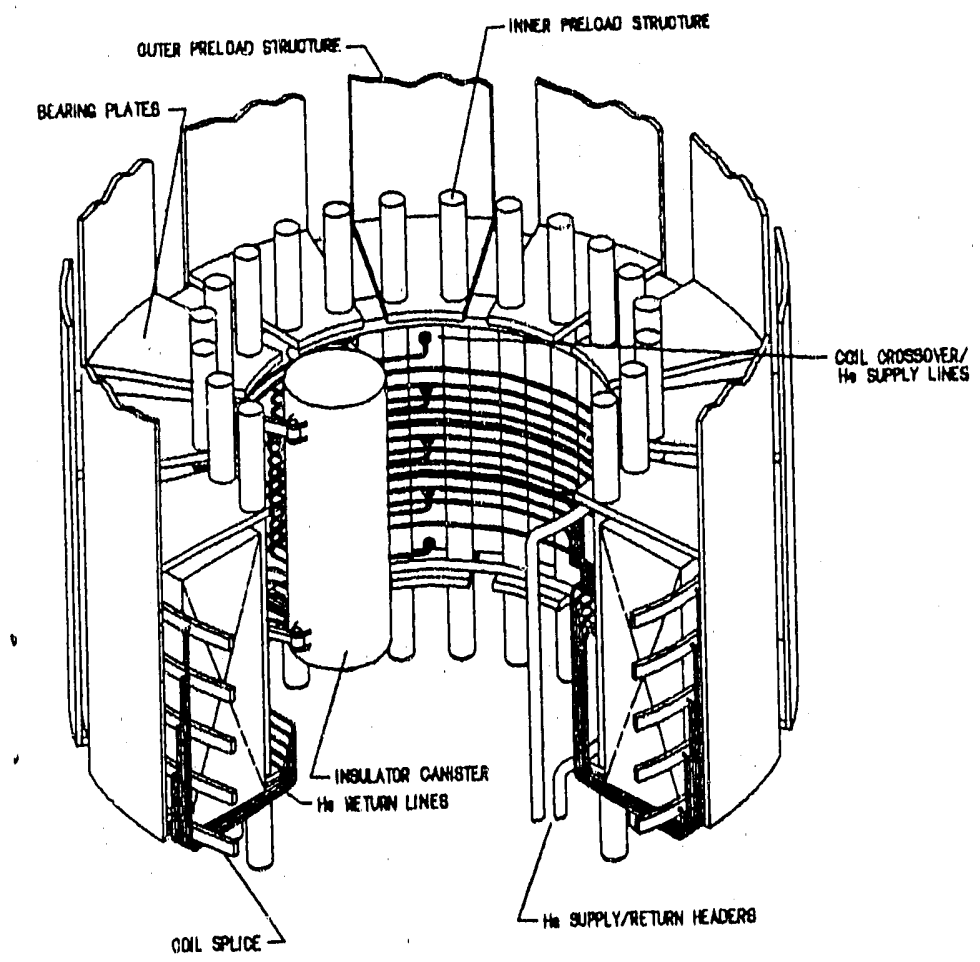

Fig. 7. Coil moduie assembiy

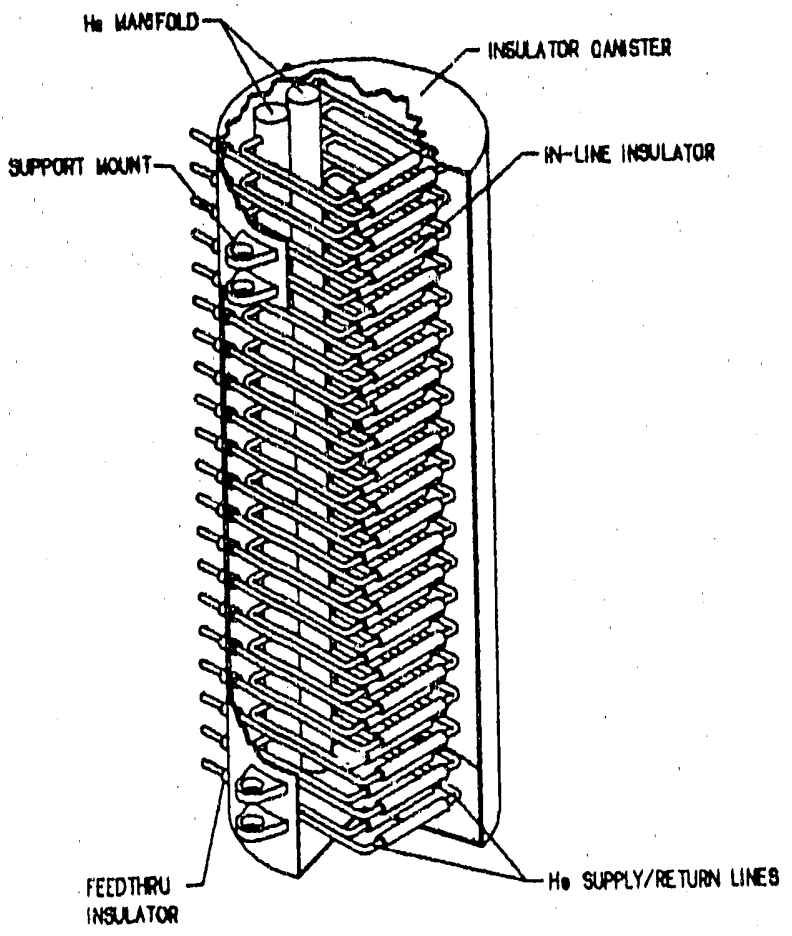

Fig. 8. Helium in-line insulator canister

\section{Final Assembly}

The final assembly is shown in Fig. 9.

Superconducting bus bars are connected to each coil module and routed down the outside of the magnet. The coil modules are stacked with the terminal connections equally spaced in the circumferential direction, thus providing eight pairs of equally spaced bus bars. This arrangement of separate current connections to each module permits each coil module to be powered individually. A high-strength steel structure is used to preload the CS coil system into compression in the vertical direction. This preloading is needed to ensure that insulation-to-conductor epoxy-bond tensile stresses do not occur during magnet operation. The structure is segmented in the circumferentia, Jirection to reduce eddy-current losses. Vertical tie rods are used in the bore of the magnet, and curved panels are used on the outside. Bus bars and He coolant lines are located in the gaps between these outside panels. The structure is stretched vertically after assembly, and shims are installed between the module stack and preload structure to achieve vertical preloading.

\section{Future Plans}

The ITER conceptual design phase is almost complete and the general plan shows a five-year-duration engineering design phase starting in about one year. Model test coils will be built and tested during the engineering phase. Material development testing will also be done during this engineering design phase. 


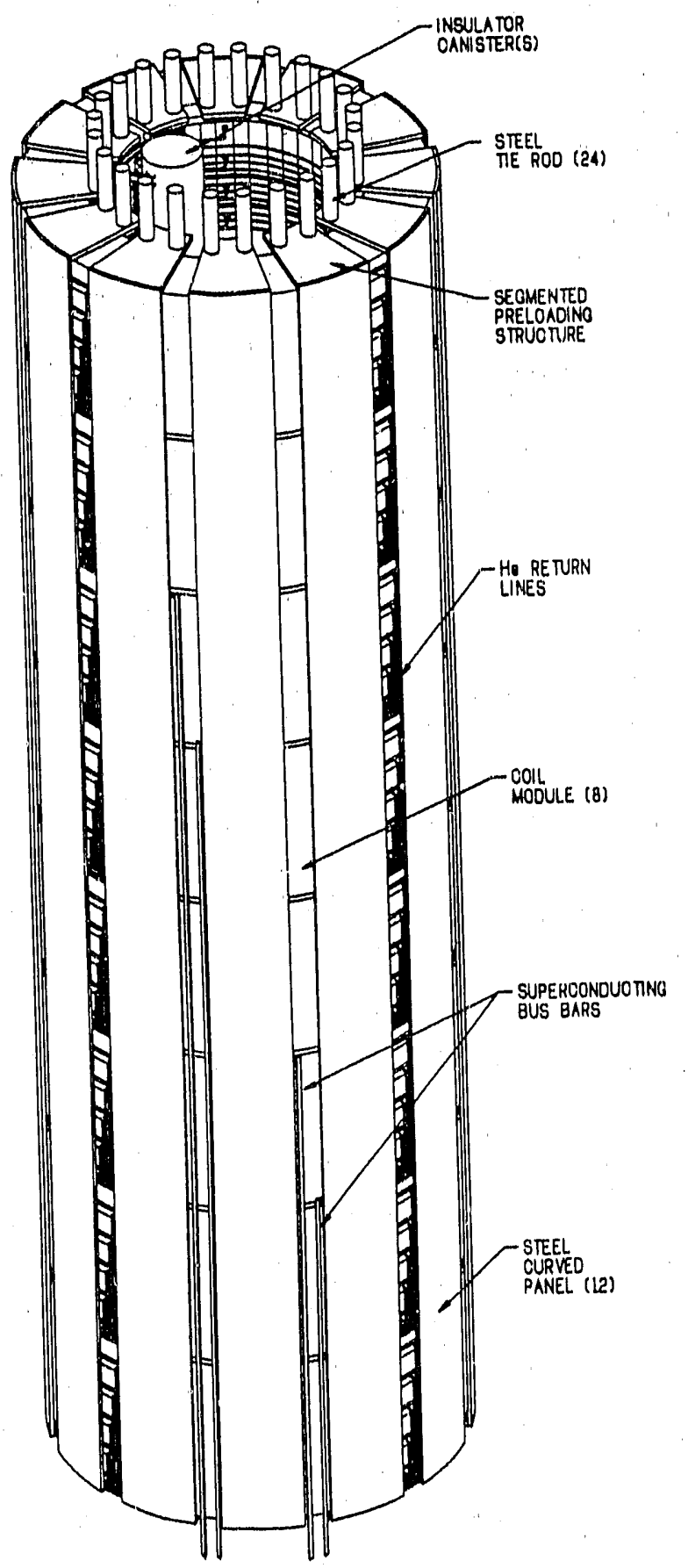

Fig. 9. Central-solenoid magnet assembly

\section{Acknowledgments}

This work was performed under the auspices of the U.S. Department of Energy by Lawrence Livermore National Laboratory under contract number ẂV́-74005-ENG-40. 

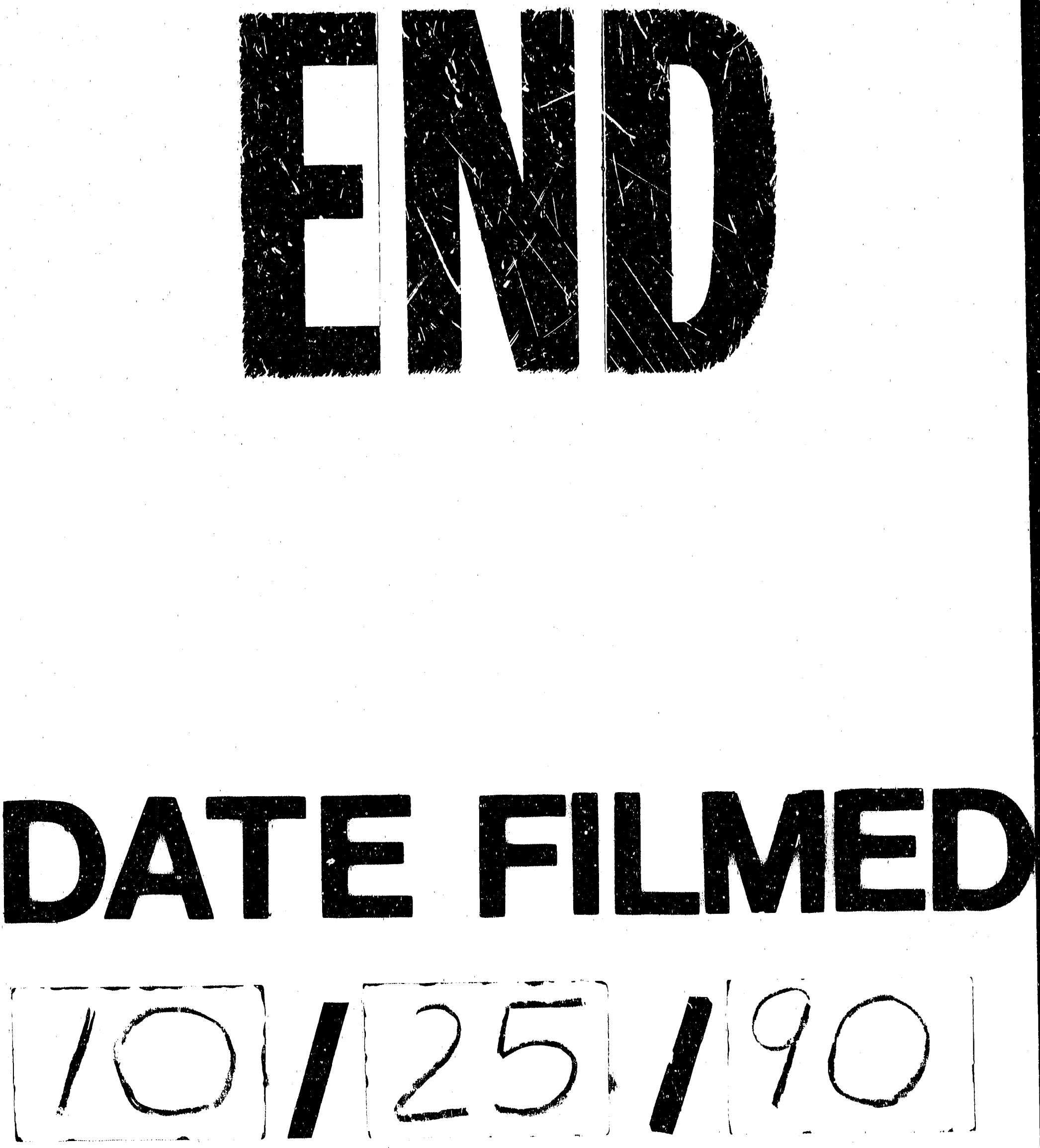
